\title{
Genotoxicity: Modern Instrumental Approaches for its Control in Environmental Objects
}

\section{Starodub NF*}

National University of Life and Environmental Sciences of Ukraine, Heroyiv Oborony St, Ukraine

\begin{abstract}
The special attention is given to methods for control of genotoxicity. Among them, the detailed analysis is given that approaches which are based on the traditional molecular genetics tests, common instrumental systems and a modern biosensor devices. It is provided as general characteristics of the developed widely dispersed, most applicable in the practice approaches and detailed description of the basic principles of their functioning. The last a specially concerns instrumental analytical methods and, in particular, cell biosensors considering the possible type of the transducers, types of cells as sensitive structures, their integration in sensor elements and way of specific signal registration. In general it is analysed sensitivity and field of application of the existed approaches for the control of total toxicity and genotoxicity.
\end{abstract}

Keywords: Genetoxicity; Molecular genetics; Control; Instrumental approaches; Biosensors

\section{Introduction}

The ecological toxicity on the living organisms may be revealed as affect on the cells in respect of their metabolic changes, or full deeds, or some reconstruction of carriers genetic information, which are presented by DNA or RNA in organisms. That is way, the specific effects may have a different implications for cells: (a) the repaired damage without any further consequences; (b) that are remained unrepaired and leads to death, as well as (c) that induce an errorprone repair pathways realizing in mutagenesis or in cancerogenesis. Last two effects are as basis for the development of the approaches for the testing of genotoxicity of environmental factors, in generally, and with involving modern instrumental methods including based on the principles of biosensorics.

\section{Traditional approaches}

Today are more than 100 different methods to assess genotoxicity but really no more than 20 test systems are practically used. The most common method in this respect was proposed Bruce Ames in 1975 and it is based on the application of His-mutants of Salmonella typhimurium which do not synthesize histidine and survive on non-histidine media only when they have mutation to wild-type His+. Revertants wild type form colonies on medium without histidine as an indicator of gene mutations [1]. Construction of test strains which are the most sensitive to the action of a mutagen is achieved by the inactivation of the excision repair system in their cells. Furthermore, the cells used in the Ames test strains have and other features that increase their sensitivity to mutagenic. In recent years test Ames has been greatly improved: automated testing procedure, increased sensitivity to certain types of mutagens.

In most cases the mutation of single genes in higher organisms are not determined since they are very rare. As a rule, it is restricted by estimation of the level of mutations in the chromosome as a whole.

The first such method for the detection and determination of the frequency of mutations in Drosophila was proposed by Muller [2,3]. This method alloved to distinguish newly arisen and existed mutations which plays the role of "closers" for crossingover (C) and has a recessive lethal effect (l) in the genotype. This chromosome was labeled by a dominant gene (Bar) which is reducing facet eye. And as the result of it the normal spherical eyes of female heterozygotes acquire bean-shape, and the males are slotted. Females of the test SIV line was crossed with irradiated males (as a mutagen may serve and chemical compound). From the first generation of females it was chosen SlV/+ persons for statement of the individual crosses. Since males with genotype $\mathrm{ClB} / \mathrm{Y}$ die the splitting on the gender in the second generation will be $2: 1$. Lack of male in the second testyfied about the lethal mutation in the $\mathrm{X}$ chromosome. Its frequency is expressed as the ratio of the number of X-chromosomes in the population. It is needed to remembe that the first generation of females between the sex chromosomes can sometimes be a double crossing-over, resulting in reduction of the true frequency of lethal mutations.

Currently C1B method has lost its practical value. Instead of it was proposed Muller-5 method. Females-line analyzers, both $\mathrm{X}$ chromosomes contain two inversions, non-lethal effect: sc8 (reduced bristles) captures a large portion of the $\mathrm{X}$ chromosome 49-inversion in the middle of the X-chromosome. As result of these reversals is substantially complete exclusion of crossing between chromosomes. Additionally both the $\mathrm{X}$ chromosome gene labeled female body and yellow color bristles yellow (y). Males in this line viable. If taken for the study of male wild-type no mutation on the $\mathrm{X}$ chromosome, then, after crossing it with the female line of the analyzer, the second generation we get to 2 phenotypic classes of females and males. If in the analyzed $\mathrm{X}$-chromosome of male lethal mutation arose in the second generation of all males will belong to the same phenotypic class (scsy d49) - yellow with reduced bristles. Moreover, each individual culture of the second generation, which is the offspring of one female F1 corresponds to one studied X chromosome from the male parent generation. Tis method and Ames test are widely used to control the chemical compounds in food products, manufacturing cosmetic agents, etc.

*Corresponding author: Starodub NF, National University of Life and Environmental Sciences of Ukraine, Heroyiv Oborony St, 15, Kyiv-03041, Ukraine, Tel: +380 44527 824; E-mail: nikstarodub@yahoo.com

Received April 07, 2015; Accepted June 12, 2015; Published June 22, 2015

Citation: Starodub NF (2015) Genotoxicity: Modern Instrumental Approaches for its Control in Environmental Objects. J Biosens Bioelectron 6: 169. doi:10.4172/2155 6210.1000169

Copyright: (c) 2015 Starodub NF. This is an open-access article distributed under the terms of the Creative Commons Attribution License, which permits unrestricted use, distribution, and reproduction in any medium, provided the original author and source are credited. 
To evaluate the ability of agents to induce chromosomal mutations widely used cytogenetic methods excluding chromosome aberrations in metaphase cells proliferating tissues in vitro or in vivo.

The disadvantage of these methods is that they are quite subjective (since they are based on microscopy) require highly skilled researchers and difficult to automate. Alternatively, a method was proposed excluding micronuclei (intracellular chromatin structures formed by the acentric chromosome fragments and whole chromosomes during anaphase due to the defect divisions of the spindle) polychromatic erythrocytes in the bone marrow of rodents, which can be automated and furthermore, applied to proliferation of any tissues including gonads. To assess the induction of chromosomal mutations in the germ cells of mammals it uses the account or dominant lethal mutations, either inherited translocations (the latter is more specific to the solution of this problem). Obviously, the maximum approximation to researchers estimate genetic risk due to the action of environmental mutagens only possible when human cells are used as test systems. In such experiments as a usually peripheral blood lymphocytes are taken and as an option - bone marrow cells, epithelial hair follicles and embryonic fibroblasts and sperm.

For the determination of the genotoxicity of some aromatic additives the Allium-test with onio tissues finds a wide application [4]. This test was used at the determination of toxicity and mutagenic effects of some food additivities too [5,6]. Seeds of this vegetable after thorough washing in a weak solution of $\mathrm{KMnO}_{4}$ were planted in Petri dishes on the moistened filter paper at kept during $72 \mathrm{~h}$ at the temperature of $22^{\circ} \mathrm{C}$ and dark. Through this time it was obtained the primary roots with length about $0,5-1 \mathrm{~cm}$. It was stated the energy and time of germination as percent of the sprouted seeds during 24 and $72 \mathrm{~h}$, respectively. Then the tissue of roots was successively treated by Folgen and Shiff reagents. Chromosomes becom reddish-purple color on the background light, not painted cells. During the cytogenetic analysis it may be determined: a) index mitotic activity; b) percent of divisions with the different steps of mitosis; c) relative number of all pathological mitoses expressed as a percentage of the total number of ones; $d$ ) relative number of single varieties pathologies mitosis expressed as a percentage of the total number of ones. In the special investigations it was made the determination of chromosomal aberrations. Cells content chromosomes with: bridges, fragments and ring in anaphase and telophase, adhesion and pulverization of chromosomes in metaphase, $\mathrm{K}$-mitosis considered as aberrant.

As result of the investigation $[5,6]$ it was stated that food aromatic additives at the concentration of $0,8-1,0 \mathrm{mg} / \mathrm{ml}$ depressed the cell divisions. As result of its the zone cell divisions was decreased in 3-6 times. Moreover, these substances aroused the formation of aneuploid and polyploid cells in Allium sepa which appeared due to K-mitosis and cariokinesis without cytokinesis.

The single cell gel electrophoresis (SCGE) or Comet assay first proposed in $1984[7,8]$ and later subsequently modified and validated [9] allows the quantitative and qualitative study of DNA damage in nuclei isolated from single cells that are embedded in agarose and transferred on microscope slides. The SCGE approach is currently used to investigate the cell response togenotoxic agents as well as to several biotic and abiotic stresses that inevitably lead to oxidative DNA damage. This technique is also utilized to characterize animal and plant mutants lacking specific DNA repair functions or genes involved in DNA damage sensing/signaling and chromatin remodeling [10-13]. Advantages and limitations of SCGE in ecogenotoxicological and biomonitoring studies have been largely discussed in animal systems [14].
Plants are exposed to a wide range of environmental pollutants and for this reason they can be used for monitoring the presence of chemical and physical mutagens in polluted habitats.

Moreover, there is interest in replacing the animal models currently used in pharmacological and toxicological research with plants. Although this seems a difficult goal, in some cases plants might enable researchers avoiding or limiting tests on animals. As conformation of this sentence the investigation of the effects of the common antipyretic agent acetaminophen (paracetamol) on the Indian mustard (Brassica juncea L.) may serve [15]. According to the 'green-liver' concept [16] detoxification of acetaminophen in the Indian mustard resembles the mammalian metabolism and high drug concentrations were found to cause oxidative stress and irreversible cellular damage in plant [16]. Within this context, SCGE application for toxicological research using plant cells as substitute for animals will necessarily require a deeper investigation to unravel the plant detoxification pathways. SCGE in plants are still limited, compared to animal systems. This technique is now emerging as a useful tool in assessing the potential of higher plants as stable sensors in ecosystems and source of information on the genotoxic impact of dangerous pollutants. Another interesting application of SCGE deals with mutation breeding or the combined use of irradiation and in vitro culture technique to enhance genetic variability in elite plant genotypes. SCGE, in combination with in situ detection of reactive oxygen species induced by $\gamma$-rays and expression analysis of both DNA repair and antioxidant genes can be used to gather information on the radiosensitivity level of the target plant genotypes.

\section{New common instrumental tests}

For detection of DNA damage it was proposed a number of high sensitive methods combined the qualitative analytical technologies with unique biomarkers such as oxidative DNA damage and stable DNA adducts. These analytical methods include HPLC-EC (High Performance Liquid Chromatography with Electrochemical Detection), LC-GC-MS, LC-MS/MS, UPLC-MS/MS, ultrasensitive CE-LIF immunoassay and 32P-post labeling test [17-20]. Despite of the ability to quantify or quantitative control of the DNA damage and/ or DNA damaging agents these methods cannot be effective for the detection and screening of unknown and potential DNA damaging agents and especially for genotoxic chemical mixture.

A number of effective microfluidic cell based handling applications have been described for control of environmental factors and have been developed. A different microfluidig systems as well as the several type of cells (bacterial, fungal, yeast, fish and mammals) were used [1719]. Progress in this field has started with the discovering in 1962 [20] and subsequent cloning of the wt-Green fluorescent protein in 1994 [21]. Now the jellyfish Aequorea victoria fluorescent proteins are the most widely used reporter proteins in all areas of biology [22].

To detect unknown DNA damaging agents and to evaluate the related DNA damage potency it is proposed the use of SOS genes which are negatively regulated by LexA repressor protein. The last binds to a consensus sequence (the SOS box) in the promoter region for those SOS genes. When DNA damage is arised, the DNA replication will be blocked at the damage sites. Therefore, large amounts of single strand DNA will appear which needs more RecA protein to bind to. The resulted RecA-ssDNA filaments provide the activated form RecA protein which interacts with the LexA repressor to facilitate the LexA repressor's self-cleavage from the SOS promoters [22]. At the early stage of SOS response the quantity of RecA protein may be significantly increased because its amount is closely related with the activity of 
recA promoter. The reporter EGFP protein under the control of recA promoter can manifest the expression of RecA protein. The fluorescence of EGFP protein can easily be tested by a fluorymeter. The fluorescent intensity can representative the activity of recA promoter and further displaying the level of SOS response of cells treated by chemicals. The expressed EGFP protein from reporter gene displays 35-times enhanced fluorescence signal over the wild type green fluorescent protein (wtGFP) due to the double mutation of Phe64Leu and Ser65Thr [23]. And the EGFP protein gets increased fluorescence intensity and photostability, enhanced $37^{\circ} \mathrm{C}$ folding efficiency and the same excitation and emission peaks with FITC which makes more general researcher for practical use of EGFP protein. In addition, the EGFP protein needs only oxygen to emit fluorescence without exogenous substrates or cofactors while enzymatic (such as beta-galactosidase) and lux reporters need reaction with other substrates to produce detectable signal with increasing cost, especially at large scale detection of chemicals [24].

The bacterial biodetection system based on the Salmonella typhimurium TA1535 cells transformed by SOS-Lux test for rapid detection of genotoxins were described [25]. It was based on the receptor reporter principle with a strong SOS-dependent promoter as receptor for DNA damage. As a response to the presence of DNAdamaging agents, bioluminescence is brought about by the induction of the promoterless luxCDABFE genes of Photobacterium leiognathi as reporter component. As a consequence of exposure to genotoxic agents the intensity of the emitted light is proportional to the concentration of the compound. The system is capable not only to determine the fact that a substance is genotoxic but it is also reflect following-up the kinetics of DNA-damage processing in the SOS system. It has already been shown that a high level of light production is induced by such concentrations of DNA-damaging agents which only scarcely affect cell survival in different bacterial species. The discrimination between genotoxic and cytotoxic potency of such test was achieved by the simultaneous measurements of the absorbance of the bacterial suspension in exchange for the cell concentration. The absence of both genotoxic and cytotoxic effect was registered if the bioluminescence did not appear and absorbance was the same as in control sample. But the decreasing both these parameters testify the cytotoxic effect of the analyzed factor. Unfortunately, changes of absorbance may be not in result of cell multiplication and growing of them metabolic activity. To control the last parameter it was proposed the determination of the expression visualization of the green fluorescent protein (GFP) from the jellyfish Aequorea victoria in the absence of substrates and other cofactors. The wild type GFP has been optimized for higher expression in bacteria and for maximal fluorescence yields using excitation wavelengths in the near UV-region (360-400 nm). This gene was inserted in the field of the lacZ initiation codon from pUC19 so that a soluble $\beta$-galactosidase-GFPuv fusion protein was appeared and measured by a fluorymeter [26]. Now it was described the expression GFPuv genes in E. coli, Staphylococcus aureus, Bacillus subtilis, Rickettsia typhi and S. typhimurium TA1535 with their including serves as tester strain in the Ames test. Bacterial bioreporter assays provide rapid, easy to execute, cost effective and field applicable solutions for monitoring water for the presence of pollutants [27]. The main principle of such construction of bacterial bioreporters is in the coupling of an innate cellular response circuit to a non-invasively measurable output. The expression vector that carries a transcriptional fusion of a gene promoter induced by the presence of a specific compound or a group of chemicals, to a DNA sequence encoding one of several possible reporter systems. Common among reporter proteins are bacterial luciferases and fluorescent proteins, which generate optical readouts $[28,29]$.
Bacteria are widely used as indicator organisms in test systems intended for the control of genotoxicity level. One of the best known systems is the Salmonella/microsome assay ("mutatest") [30]. Other induction assays ("inductest") is based on prophage clts857 [31].

It was developed the SOS chromotest as colorimetric the bacterial test for detecting DNA-damaging agents which arose induction of the function of $\beta$-galactosidase gene under control of the sfiA included in lacZ operon of Escherichia coli K-12 [32]. The SOS function involved in cell division inhibition. This $S O S$ chromotest requires only a single strain and simple colorimetric determination of two enzymes: $\beta$-galactosidase and alkaline phosphatase. In the comparative investigations the SOS chromotest was more sensitive than the "inductest" and "mutatest".

Based on the transcriptional response of yeast cells to DNA damage various automatised genotoxicity test systems have been developed [33] one of which was commercionalized as GreenScreen GC assay [34]. It was developed even a human-cell based GreenScreen HC assay utilizing a GADD45a-GFP [35].

Today the panel of the developed systems content a wide set of tests based on in vitro measuring guanine oxidation in DNA, yeast, prokaryotic, fish embryos and mammalian cells. Among the bacterial tests the DNA damage dependent induction of the SOS repair system are the next tests: SOS-Chromo [36], Umu [37], Lux-Fluoro [38], VitoTOX ${ }^{\oplus}[39]$ and some biosensors variants [40]. The Lux-Fluoro test is a unique combination of two bioassays [41], which coincidentally measure genotoxicity (SOS-Lux test) and cytotoxicity (Lac-Fluoro test) of substances and mixtures of substances. The SOS-Lux assay, like the SOS-Chromo test or the Umu test, is based on the measurement of DNA damage-dependent induction of the bacterial SOS system in genetically modified Salmonella typhimurium TA1535 bacteria [42], which have been transformed with the plasmid pPLS-1 carrying the promoter less lux genes of Photobacterium leiognathi as reporter element under the control of a DNA damage-dependent SOS promoter from ColD as sensing element [43]. This system reacts to agents, which induce DNA damages inside these bacterial cells with the dose-dependent production of bioluminescence. The bioluminescence as a signal for DNA damage is an enzymatic reaction of a photolyase with its specific substrate, both encoded by the luxCDABFE genes of Photobacterium leiognathi, in presence of oxygen. Since the bioluminescent light can be registered by an appropriate detector like a photomultiplier without destroying the cells, the kinetics of the processing of the DNA damage by the SOS system can be followed in living cells. The SOS-Lux test as a bioassay for genotoxicity can be used partly or fully automatically for routine measurements and can be employed for high throughput screening. The analogue Lac-Fluoro-test detects the cellular responses to cytotoxins [44]. It is based on the constitutive expression of green fluorescent protein (GFP) mediated by the bacterial protein expression vector pGFPuv as GFPuv expression is not under regulatory constraints in Salmonella typhimurium, due to the lack of a functional lacI repressor in this species. In response to cytotoxic agents, this system reacts with a dose-dependent reduction of GFPfluorescence. The recombinant S. typhimurium strains carrying either the SOS-Lux plasmid or the lac-GFPuv plasmid are used to determine in parallel in one well of a microplate the genotoxic and the cytotoxic potential of the test compounds. Light and fluorescence emission as well as absorption of cells in the test samples and in the controls are measured in the microplate luminometer-fluorometer-photometer combination Victor2 and the calculated luminescence induction as well as fluorescence reduction is used to determine the genotoxic and/ or cytotoxic potential of the applied compound. Victor 2 device is a 
complete platform for quantitative detection of fluorescence, flash or glow luminescence, absorbance and photometry using specific filters. The instrument was equipped with the following filters: absorbance: at $490 \mathrm{~nm}$ ( $20 \mathrm{~nm}$ band width), fluorescence: excitation at $405 \mathrm{~nm}(15 \mathrm{~nm}$ band width), emission at $510 \mathrm{~nm}$ (10 $\mathrm{nm}$ band width), luminescence: open.

Already it was shown that the above mentioned reporter system reacts with a high level of light production to different classes of DNA damaging agents already at concentrations that have nearly no effect on cell survival in S. typhimurium TA1535 cells [3]. For higher concentrations, when tested agents induce cytotoxic effects, the determination of SOS induction is influenced by the proportion of dying cells of the exposed population. As simultaneous measurements of luminescence and fluorescence allow for discrimination between genotoxic and cytotoxic potency of the tested compound it is possible to correct light output yields for the proportion of surviving cells. The resulting induction factor Fi can be used to identify genotoxicity: a test compound is considered to be cytotoxic, if fluorescence and/ or bioluminescence of exposed cells are decreased; a test compound is considered to be genotoxic if bioluminescence is increased and induction factors Fi exceed double the amount of control levels. It was proved the test's special value in respect to its advantages over other test systems: (i) the in vivo measurement itself is non-disruptive and can be repeated several times with 96 samples in parallel; (ii) the whole kinetics of the SOS induction by a DNA-damaging substance can be followed up for several hours in the same sample, thereby stating possible growth delays which cannot be seen in other tests and which may falsify comparisons of substances when only one measurement is performed after a fixed period of time; and (iii) first indications on a substance's genotoxic potential can already be derived after $2-3 \mathrm{~h}$ of incubation [39,43-45]. Genotoxic chemical and environmental samples were successfully identified by the SOS-Lux test, simultaneously the Lac-Fluoro test confirmed the absence of cytotoxic components interfering with the results of the SOS-Lux test. The lower detection limit of 4-nitroquinoline 1-oxide was $8.1 \times 10^{-3} \mu \mathrm{gL}^{-1}$. No matrix effect was observed with the Lux-Fluoro test. The 2 -aminoanthracene was identified to showthe highest genotoxic response of all tested substances with detection limit after metabolic activation with $\mathrm{S} 9$ of $4 \mu \mathrm{gL}^{-1}$. The lowest concentration of $\mathrm{N}$-methyl-N'-nitro-N-nitrosoguanidine detected as genotoxicwas $0.216 \mu \mathrm{gL}^{-1}$. The not filtered surface water showed a limited genotoxic reaction only after incubation with S9 fraction in a $1 \%$ dilution and no concentration dependency. The LuxFluoro test showed a strong positive signal for the effluent water of a textile industry in demonstrating the genotoxicity of this sample.

Mammalian $\mu$-FADU assay which is based on alkaline DNA unwinding have recently been presented [46]. This assay is operated in a 96-well format, thus greatly increasing throughput. The number of cells required has been reduced to less than 10,000 per data point. The threshold for detection of X-ray-induced DNA strand breaks is $0.13 \mathrm{~Gy}$. The total assay time required for a typical experiment to assess DNA strand break repair is 4-5 hours [47]. It has established a robust and convenient method measuring of formation and repair of DNA single-strand breaks in live cells.

The special attention is belong to canavanine, $\alpha$-factor, 5-fluoroorotic acid (5-FOA) and [48,49]. 5-FOA is nontoxic, but it can be converted into toxic 5-fluoro-uracil by the uracil biosynthesis pathway. The product of the URA3 gene catalyzes a key step in this process. Therefore, 5-FOA predominantly selects for ura3 loss-offunction mutants. Canavanine is a toxic arginine analog, whose uptake requires the arginine transporter. It selects for loss-of-function mutants of this transporter, which is encoded by the CAN1 gene. $\alpha$-Factor is a peptide pheromone secreted by mating-type a (MATa) cells. Binding of the pheromone to the Ste2 receptor on a MATa cell signals through a MAP-kinase cascade to initiate the mating-response genes and a G1 arrest. Wild-type MATa cells secrete a protease, Bar1, which degrades $a$-factor. Deleting BAR1 prevents growth on medium containing $a$-factor and allows us to measure the rate of resistance to $a$-factor using the fluctuation assay.

Next type of the approaches for the control of genetoxicity is ChIPsequencing, also known as ChIP-Seq or ChIP-seq [50,51]. This method is used to analyze protein interactions with DNA. ChIP-seq combines chromatin immunoprecipitation (ChIP) with massively parallel DNA sequencing to identify the binding sites of DNA-associated proteins. It can be used to map global binding sites precisely for any protein of interest. Previously, ChIP-on-chip was the most common technique utilized to study these protein-DNA relations.

In general there is necessary to underline again that there is proposed more one hundred common approaches for the determination of the genetoxicity as it was mentioned above but now the practice demands to develop express and automatically methods which could be developed on the basis of the principles of biosensorics.

\section{Biosensor tests}

The start in the development of these approaches for the determination of genotoxicity are was done not long ago. Their appearance was stimulated not wishing to appreciate medium toxicity only and to have information about gene toxic effect in regime on line.

The yeast-based biosensors consist of two components: the RNR3 gene in lacZ system which serve as sensor since it induces during the DNA damage only and reporter. In spite that a series of genetic manipulations allowed to make the RNR3-lacZ system highly sensitive but for application in biosensors it should be improved [52]. So, the lacZ reporter based on a colorimetric determination of the $\beta$-galactosidase activity, which requires cell disruption. To achieve high efficiency and simplicity operating genotoxic testing system lacZ reporter was replaced by a yEGFP gene encoding yeast-enhanced green fluorescent protein which was optimized for expression in Saccharomyces cerevisiae early $[53,54]$. Recombinant yeast (S. cerevisiae) containing fluorescent markers such as green or red fluorescent protein (GFP or RFP) are ideal candidates for microscreening. GreenScreenTM has been employed for screening a different genotoxic industrial products and environmental contaminants [55].

Due to the number genetic investigations it was proposed a yeastcell based HUG1-GFP biosensor as a sensitive genotoxic testing system to detect multiple genotoxins. HUG1 promotor (hydro-xyurea and UV, gamma radiation induced), which is regulated by the Meclcheck point pathway [56,57]. At the comparison of two biosensors it was stated [55] that maximum induction and linear regression of the HUG1-yEGFP biosensor is about twice as sensitive as RNR3-yEGFP one. Perhaps the most significant improvement in such types of biosensors concerns manipulation with seven genes from among dozens of candidate for the disarming all these systems that play roles in the protection of yeast cells from effects of environmental factors. As results of it there is possibility to created a hypersensitive host strain that enables reporters like HUG1-yEGFP and RNR3-yEGFP to detect extremely low doses of genotoxins with a more than 300 -fold increase in sensitivity and in certain aspects surpasses the current industrial gold standards like 
theAmes test and SOS chromotest. It should be noted that the septuple mutant strain can be utilized byother yeast genotoxicity testing systems including those based on cell survival or mutagenesis and can also be further improved in combination with either in vivo or in vitro metabolic activation of certain chemicals. The yEGFP based reporter in combination with appropriate mutant strains can also be utilized to detect other non-genotoxic environmental chemicals.

In spite of existed improving biosensors based on yeast transcriptional response to genotoxicity there is necessary in investigation of many agents which involved in effect on the metabolic activation in mammals to become genotoxic and carcinogenic. Unfortunately such responsible activation systems are largely lacking in yeast cells. That is why, the future research should be directed towards humanizing yeast cells for the metabolic activation of pre-genotoxic/ pre-carcinogenic compounds and application of new type system in biosensors for express screening of environmental factors.

It was constructed a bacterial biosensor in an E. coli strain with a transformed egfp gene as a reporter gene under the control of the promoter of recA gene and developed an SOS-EGFP test. By this test, the biosensor cells treated by chemicals can produce brighter fluorescence than the untreated control if the chemicals can induce substantial DNA damage [58]. The constructed biosensor is probably useful to simultaneously evaluate the genotoxicity and cytotoxicity.

The products of a number of SOS-dependent genes are involved in DNA-repair-mechanisms which are activated at the occurrence of DNA single strands. Such DNA lesions are induced by compounds that form the DNA-adducts. The expression of the SOSgenes is regulated by the LexA protein that specifically binds to SOS-responsive promoter sequences. In order to detect the SOS-response the SOS-sensitive promoters like the recA or umuDC genes are fused to lac $\mathrm{Z}$ or phoA encoding the enzymes $\beta$-galactosidase or alkaline phosphatase). For the bacterial test systems it is of crucial importance to mimic the metabolism of xenobiotics that takes place in the liver of vertebrates and which can lead to a formation of bio-activated and thus genotoxic intermediates. Usually, this is done by the addition of the S9-fraction that is prepared from the liver of induced rodents. It is composed of a complex mixture of enzymes involved in the metabolism of xenobiotics, in particular the microsomal bound cytochrome-P450dependent monooxygenases. They catalyze the oxidation of organic compounds by molecular oxygen. The cytochrome-P450-dependent monooxygenases are activated by a reduction step concomitantly with the consumption of NADPH [59]. The electrochemical signal can be detected via para-aminophenyl $\beta$-d-galactopyranoside (pAPG) since the reporter enzyme, $\beta$-galacosidase cleaves the glycosidic bond in this substance. The reaction product p-aminophenol (pAP) can be oxidized electrochemically to p-iminoquinone even it is possible without cell-lysis [60]. Direct electrochemical signal detection is preferable in the comparison with others ones since the use of a simple set of electrodes would greatly reduce the complexity, size and costs that are typically associated with the optical detection.. However, it has yet to be proven that electrochemistry can also compete in terms of sensitivity with the colorimetric signal detection. This is of special interest because of the mandatory presence of the uncharacterized mixture of potentially electro-active enzymes and metabolites (S9fraction of liver homogenate), as well as several cofactors (e.g. NADP) in the standard assay reaction, that are added to metabolically activate pre-genotoxic substances. These compounds might interfere with the electrochemical signal detection and decrease its sensitivity. It was reported [61] about the using electrochemiluminescent arrays for the genotoxicity testing of metabolites of benzo[a]pyrene that are generated in situ by various immobilized cytochrome (cyt) P450 or imbedded microsomes as their source. It was described [61] the aforementioned electrochemiluminescent arrays for the detection of the DNA-damage without any cellular context, i.e. the formation of the adducts with the purified DNA and not a cellular response. The chromo-amperometric electrochemical signal was characterized by the detection following the induction of the bacterial SOS-response in the presence of S9-mix. It was demonstrated that the unique substrate mediated electrochemical detection is simple to use, can be integrated on a miniaturized whole cell bio chip and yield satisfactory results in comparison to the respective ISO standard [62]. Chromo-amperometry based on the screen printed electrodes was compared with a standardized colorimetric assay for the detection of genotoxic samples by reporter gene induction (lacZ) via the bacterial SOS-system. The amperometric method was optimized in terms of substrate concentration for the reporter gene $\beta$-galactosidase that cleaves $\mathrm{pAPG}$ to $\mathrm{pAP}$ which in turn is oxidized to $\mathrm{p}$-iminoquinone at the electrode. It was found that a final concentration of $6 \mathrm{mM}$ of pAPG is suitable to guarantee its cleavage by pseudo zero-order kinetics even if the reporter enzyme is strongly induced. By means of linear sweep voltammetry it was shown that a potential range of $300-400 \mathrm{mV}$ is most suitable for the detection of pAP in a potential whole cell-based biosensor even in the presence of a large excess of pAPG. A comparison of the colorimetric and electrochemical detection methods shows a high correlation of the determined SOS-induction factors indicating the usability of the amperometric signal detection in principle. But the noise level of the electrochemical detection at $300 \mathrm{mV}$ is substantially increased compared to the colorimetric assay limiting its potential for the assessment of environmental samples because of a decrease in sensitivity. In contrast, the noise level of the amperometric detection of pAP at $400 \mathrm{mV}$ is very similar to the colorimetric standard method. Such biosensor will contain bacterial reporter strains and all necessary compounds for the metabolic activation of xenobiotics (S9-fraction and cofactors) which are lyophilized on top of the electrode in a small reaction chamber. The freeze-dried biological compounds could be dissolved by the sample before the eventual induction of the SOSresponse. The electrodes will be exchanged after the measurement [63].

Today it was proposed many mammalian cell-based gene mutation assays but only four cell lines of Chinese hamster V97 and CHO cells, human lymphoblastoid TK6 cells, mouse lymphoma L5178Y cells as well as three genetic loci of HPRT (hypoxanthineguanine phosphoribosyltransferase), TK (thymidine kinase) and the cell membrane $\mathrm{Na}+/ \mathrm{K}+$ ATPase genes are well validated and widely used. But they have a low sensitivity that is still a problem in these mammalian cell-based gene mutation assays [64].

In mammalian cells the transcription factor p53 works as a guard keeper of the genome by inducing DNA damage repair, cell cycle arrest and apoptosis in response to cellular stresses leading to DNA damage, thus it is also called tumor suppressor. The DNA repair gene P53R2 which encodes a subunit of ribonucleotide reductase is a p53target gene activated in response to cellular DNA damage. The p53R2mediated luciferase reporter gene were used in the bioassay system for genotoxicity detection using human cells with wild-type p53 $[65,66]$. Validation of this assay system indicated that it could be a rapid and reliable tool in the screening of genotoxic chemicals. The GADD45amediated GFP reporter gene was applied in the bioassay system for the genotoxicity detection in human TK6 cells. It was found that this assay system had both high specificity and high sensitivity in genotoxicity detection of different genotoxicants $[67,68]$. The cyclin-dependent kinase $1 \mathrm{~A}$ inhibitor of $\mathrm{p} 21 \mathrm{CIP} 1 / \mathrm{WAF} 1$ is the major downstream target 
Citation: Starodub NF (2015) Genotoxicity: Modern Instrumental Approaches for its Control in Environmental Objects. J Biosens Bioelectron 6: 169. doi:10.4172/2155-6210.1000169

gene of activated p53 and is responsible for causing cell cycle arrest following DNA damage. These p21-mediated eGFP reporter gene were used in the bioassay system for genotoxicity detection in human hepatoma HepG2 cells. A fish cell biosensor system for genotoxicity detection was created by the integration of three plasmids of pGL3-p21luc (p21 promoter linked to firefly luciferase gene), pRL-CMV (CMV promoter linked to Renilla luciferase gene) and pcDNA3.1 into FG cells [68]. In tht biosensor system two reporter genes were introduced and they were simultaneously expressed and measured sequentially within a single test system. The expression of firefly luciferase is correlated with the DNA damage response to genotoxicants. The expression of Renilla luciferase serves as an internal control normalizing the experimental variability caused by differences in cell viability or extraneous influences in dual-reporter assays including pipetting volumes, cell lysis efficiency and assay efficiency. It was obtained more reliable data by this fish cell biosensor system in comparison with the single luciferase reporter systems and was concluded that the fish cell biosensor system may become a specific and sensitive tool for genotoxicity detection of new chemicals and drugs. Moreover, that the FG cell line has been established and widely used to study the toxic effects and mechanisms of environmental pollutants on fish species [69,70]. Unlike mammalian cells, FG cells can be easily maintained in a wide range of temperatures from $15^{\circ} \mathrm{C}$ to $30^{\circ} \mathrm{C}$. This will provide an extraordinary merit in the shelf life and transportation once this fish cell biosensor system is marketed.

The one of very important problem which arouses at the creation of any biosensors is the optimization of the integration of the biological selective structures with the transducer surface. Especially it is appeared at the application of the different types of cells. As a rule for this purpose the number of organic and polymeric materials [71-73]. The recombinant bacteria were incorporated in soft gels such as agarose, polyacrylamide or calcium and strontium alginates and sol-gel $[74,75]$. The main problems at the immobilization of genetic engineering of bacteria for the expression of the reporting enzymes in response to physiological stress conditions are connected with the soft hydrogel supports, biodegradation susceptibility, diffusion limitation due to the thick films involved, low physical deformation resistance and the instability of the alginates in calcium-poor solutions and in the presence of calcium chelates. It was used the encapsulation of cells by a dialysis membrane [76] and that based on a glycerol-acryl vinyl acetate copolymer latex [77]. A very good results were obtained with the application of sol-gel when all the immobilized bacteria maintained viability and luminescence activity for several months [75]. The bacteria-silicate hybrids can be used either as disposable sensors or in multiple use of sensing test-kits and they can be also integrated in early warning devices operated in continuous flow conditions.

\section{Conclusion}

The control of the genotoxicity level of the objects has a special and very important significance since we have now a increasing loading environment by the different chemical substances. Some of them may have not only general toxicity and can generate mutagenic or different genetic effects too. Moreover, there may even be a situation that genotoxicity appears at the low concentrations of the active agent when the overall its toxicity is still quite difficult to detect. At present, there are many approaches that have already convincingly being used in practice. Significant progress in this direction achieved with the development of instrumental methods, but much progress in the control of genotoxicity contributed to the development of biosensor approaches that are able to meet all requirements of the practice, not only in terms of sensitivity analysis but its simplicity, fulfilment in on- line regime and in field condition. There are high hopes not only on progress in the development of biosensor methods in further, but also on the intensification of their practical application. The main directions of both ways of the development of the instrumental methods including biosensors is outlined in this article.

\section{References}

1. Medical Planet. Genotoxicity. The test system for genotoxicity.

2. Demerec M (1948) Introduction of mutations in drosophila by dibenzanthracene Genetics 33: 337-348.

3. Herskowitz IM (1950) The Differential Induction of Lethal Mutations by Formalin in the Two Sexes of Drosophila. Science 112: 302-303.

4. Fiskesjo G (1988) The Allium test - an alternative in environmental studies: the relative toxicity of metal ions. Mutation Res 197: 243-260.

5. Taran MV, Shavanova KE, Marchenko OA (2011) Investigtion of mutagenic effect of synthetic flavors. Abstr of Int Sci Conf of Young Scientists 9.

6. Taran MV, Shavanova KE (2011) Effect of Food Additives on mitotic activity Allium sepa. Abst Int. Conf "Youth and progress of biology" 171-172.

7. Ostling O, Johansons KJ (1984) Microelectrophoretic study of radiation-induced DNA damage in individual mammalian cells. BBRC 123: 291-298.

8. Collins AR (2004) The comet assay for DNA damage and repair:principles, applications and limitations. Mol Biotechnol 26: 249-261.

9. McArt DG, McKerr G, Saetzler K, Howard CV, Downes CS (2010) Come sensitivity in assessing DNA damage and repair indifferent cell cycle stages. Mutagenesis 25: 299-303.

10. Wentzel JF, Gouws C, Huysamen C, van Dyk E, Koekemoer G (2010) Assessing the DNA methylation status ofsingle cells with comet assay. Anal Biochem 400: 190-194.

11. Bohmdorfer G, Schleiffer A, Brunmeir R, Ferscha S, Nizhynska V, et al. (2011) GMI1, a structural-maintenance-of-chromosomes-hinge domain-containing protein, is involved insomatic homologous recombination in Arabidopsis. Plant J 67: 420-433.

12. Kamisugi Y, Schaefer DG, Kozak, Charlot F, Vrielynck N, et al. (2012) MRE11 and RAD50, but not NBS1 are essential for gene targeting in the moss Physcomitrella patens. Nucleic Acids Res 40: 3496-3510.

13. Kumaravel TS, Vilhar B, Faux SP, Jha AN (2009) Comet assay measurements: a perspective. Cell Biol Toxicol 25: 53-64.

14. Bartha B, Huber C, Harpaintner R, Schroder P (2010) Effects of acetaminophen in Brassica juncea L. Czern.:investigation ofup-take, translocation, detoxification, and the induced defense pathways. Environ Sci Pollut Res Int 17: $1553-1562$.

15. Schroder $P$, Collins CJ (2002) Conjugating enzymes involved in xenobiotic metabolism of organic xenobiotics in plants. Int J Phytorem 4: 247-265.

16. Garcia-Alonso, Greenway J, Hardege GM, Haswell JD, Stephen J (2009) A prototype microfluidic chip using fluorescent yeast for detection of toxic compounds. Biosensors and Bioelectronics 24: 1508-1511.

17. Rhee SW, Taylor AM, Tu CH, Cribbs DH, Cotman CW, et al. (2004) Patterned cell culture inside microfluidic devices. Lab Chip 5: 102-107.

18. Zeringue HC, Rutledge JJ, Beebe DJ (2004) Early Mammalian Embryo Development Depends on Cumulus Removal Technique. Lab Chip 5: 86-90.

19. Shimomura O, Johnson $\mathrm{FH}$, Saiga $\mathrm{Y}$ (1962) Extraction, purification and properties of aequorin, a bioluminescent protein from the luminous hydromedusan, Aequorea. J Cell Comp Physiol 59: 223-239.

20. Chalfie M, Tu Y, Euskirchen G, Ward WW, Prasher DC (1994) Green fluorescent protein as a marker for gene expression. Science 263: 802-805.

21. Dammeyer TH, Tinnefeld PH (2012) Engineered fluorescent proteins illuminate the bacterial periplasm. Comput Struct Biotechnol J 3.

22. Nelson DL, Cox MM (2005) Lehninger: Principles of Biochemistry (4th edn) W.H. Freeman and Company, New York, 1098.

23. Cormack BP, Valdivia RH, Falkow S (1996) FACS-optimized mutants of the green fluorescent protein (GFP). Gene 1: 33-38. 
Citation: Starodub NF (2015) Genotoxicity: Modern Instrumental Approaches for its Control in Environmental Objects. J Biosens Bioelectron 6: 169. doi:10.4172/2155-6210.1000169

Page 7 of 8

24. Vollmer AC, Belkin S, Smulski DR, Van Dyk TK, Larossa RA (1997) Detection of DNA damage by use of Escherichia coli carrying recA'::lux, uvrA'::lux, or alkA'::lux reporter plasmids. Appl Environ Microbiol 7: 2566-2571.

25. Baumstark-Khan CH, Rode A, Rettberg P, Horneck G (2001) Application of the Lux-Fluoro test as bioassay for combined genotoxicity and cytotoxicity measurements by means of recombinant Salmonella typhimurium TA1535 cells. Anal Chim Acta 437: 23-30.

26. Crameri A, Whitehorn EA, Tate E, Stemmer WP (1996) Improved green fluorescent protein by molecular evolution using DNA shuffling. Nat Biotechnol 14: 315-319.

27. Elad T, Belkin S (2013) Broad spectrum detection and "barcoding" of water pollutants by a genome-wide bacterial sensor array.

28. Van der Meer JR, Belkin S (2010) Where microbiology meets microengineering: design and applications of reporter bacteria. Nat Rev Microbiol 7: 511-522.

29. De las Heras A, Carreño CA, Martínez-García E, de Lorenzo V (2010) Engineering input/output nodes in prokaryotic regulatory circuits. FEMS Microbiol Rev 34: 842-865.

30. Ames BN, McCann J, Yamasaki E, Choi E (1975) Detection of carcinogens and mutagens in Salmonella/microsome test: assay of 300 chemicals. Mutant Res 31: 347-364

31. Ho YL, Ho SK (1981) Screening of Carcinogens with the Prophage $\lambda \mathrm{cl}$ ts 857 Induction Test Cancer Res 41: 532-536.

32. Quillardet $P$, Huisman O, D'Ari R, Hofnung M (1982) SOS chromotest, a direct assay of induction of an SOS function in Escherichia coli K-12 to measure genotoxicity. Proc Natl Acad Sci 79: 5971-5975.

33. Fu Y, Pastushok L, Xiao W (2008) DNA damage-induced gene expression in Saccharomyces cerevisiae. FEMS Microbiol Rev 32: 908-926.

34. Ichikawa K, Eki T (2006) A Novel Yeast-Based Reporter Assay System for the Sensitive Detection of Genotoxic Agents Mediated by a DNA DamageInducible LexA-GAL4 Protein. J Biochem 139:105-112.

35. Hastwell PW, Chai LL, Roberts KJ, Webster TW, Harvey JS, et al. (2006) Highspecificity and high-sensitivity genotoxicity assessment in a human cell line: Validation of the GreenScreen HC GADD45a-GFP genotoxicity assay. Mut Res 607: $160-175$.

36. Quillardet P, Hofnung M (1993) The SOS chromotest: a review. Mutat Res 297: 235-279.

37. Oda Y, Nakamura S, Oki I, Kato T, Shinagawa H (1985) Evaluation of the new system (umu-test) for the detection of environmental mutagens and carcinogens. Mutat Res 147: 219-229.

38. Baumstark-Khan C, Khan RA, Rettberg P, Horneck G (2003) Bacterial LuxFluoro test for biological assessment of pollutants in water samples from urban and rural origin. Anal Chim Acta 487: 51-60.

39. Verschaeve L, Van Gompel J, Thilemans L, Regniers L, Vanparys P, et al. (1999) VITOTOX bacterial genotoxicity and toxicity test for the rapid screening of chemicals. Environ Mol Mutagen 33: 240-248.

40. Polyak B, Bassis E, Novodvorets A, Belkin S, Marks RS (2000) Optical fiber bioluminescent whole-cell microbial biosensors to genotoxicants. Water Sci Technol 42: 305-311

41. Rettberg P, Bandel K, Baumstark-Khan C, Horneck G (2001) Increased sensitivity of the SOS-LUX-Test for the detection of hydrophobic genotoxic substances with Salmonella typhimurium TA1535 as host strain. Anal Chim Acta 426: 167-173.

42. Ptitsyn LR, Horneck G, Komova O, Kozubek S, Krasavin EA (1997) A biosensor for environmental genotoxin screening based on an SOS lux assay in recombinant Escherichia coli cells. Appl Environ Microbiol 63: 4377-4384.

43. Baumstark-Khan $\mathrm{CH}$, Rabbow E, Rettberg P, Horneck G (2007) The combined bacterial Lux-Fluoro test for the detection and quantification of genotoxic and cytotoxic agents in surface water: Results from the "Technical Workshop on Genotoxicity Biosensing". Aquatic Toxicol 85: 209-218.

44. Rabbow E, Rettberg P, Baumstark-Khan C, Homeck G (2003) The SOSLuxLac-Fluoro toxicity test on the Intern. Space Station (ISS). Adv Space Res 31 : 1513-1524.

45. Baumstark-Khan C, Horneck G (2007) Results from the "Technical Workshop on Genotoxicity Biosensing" on the micro.scale fluorometric assay of deoxyribonucleic acid unwinding. Anal Chim Acta 593: 75-81.

46. Moreno-Villanueva M, Pfeiffer R, Sindlinger TH, Like A, Müller M, et al. (2009) A modified and automated version of the 'Fluorimetric Detection of Alkaline DNA Unwinding' method to quantify formation and repair of DNA strand breaks. BMC Biotechnol 9: 39

47. Zhang M, Zhang C, Jia Li, Hanna M, Zhang X, et al. (2011) Inactivation of YAP1 Enhances Sensitivity of the Yeast RNR3-lacZ Genotoxicity Testing System to a Broad Range of DNA-Damaging Agents. Toxicol Sci 120: 310-321.

48. Brusick D (1987) Principles of Genetic Toxicology. Springer Sci.+Bisness Media, New-York.

49. Lang GI, Murray AW (2008) Estimating the Per-Base-Pair Mutation Rate in the yeast Saccharomyces cerevisiae. Genetics 178: 67-82.

50. Zhang Y, Liu T, Meyer CA, Eeckhoute J, Johnson DS, et al. (2008) Modelbased analysis of ChIP-Seq (MACS). Genome Biol 9:137.

51. Blow MJ, McCulley DJ, Li Z, Zhang T, Akiyama JA, et al. (2010) ChIP-seq identification of weakly conserved heart enhancers. Nat Genet 42: 806-810.

52. Cormack BP, Bertram G, Egerton M, Gow NA, Falkow S, Brown AJ (1997) Yeast-enhanced green fluorescent protein (yEGFP): a reporter of gene expression in Candida albicans. Microbiology 143: 303-311.

53. Tsien RY (1998) The green fluorescent protein. Annual Rev of Biochem 67 509-544.

54. Ting W, Zhang C, Xu X, Hanna M, Zhang M, et al. (2013) Construction and evaluation of two biosensors based on yeast transcriptional response to genotoxic chemicals. Biosens and Bioelectron 44: 138-145.

55. Benton MG, Glasser NR, Palecek SP (2007) The utilization of a Saccharomyces cerevisiae HUG1P-GFP promoter-reporter construct for the selective detection of DNA damage. Mutat Res 633: 21-34.

56. Benton MG, Glasser NR, Palecek SP (2008) Deletion of MAG1 and MRE11 enhances the sensitivity of the Saccharomyces cerevisiae HUG1P-GFP promoter-reporter construct to genotoxicity. Biosensors and Bioelectronics 24 736-741.

57. Chen Zh, Lu M, Zou D, Wang H (2012) An E. coli SOS-EGFP biosensor for fast and sensitive detection of DNA damaging agents. J of Environ Sci (China) 24: 541-549.

58. Ku WW, Bigger A, Brambilla G, Glatt H, Gocke E, et al. (2007) Strategy for genotoxicity testing-metabolic considerations. Mutat Res 627: 59-77.

59. Mie Y, Kowata K, Hirano Y, Niwa O, Mizutani F (2008) Comparison of enzymatic recycling electrodes for measuring aminophenol: development of a highly sensitive natriuretic peptide assay system. Anal Sci 24: 577-582.

60. Buchingera S, Grill P, Morosow V, Ben-Yoavc H, Shacham-Diamandc $Y$, et al (2010) Evaluation of chrono-amperometric signal detection for the analysis of genotoxicity by a whole cell biosensor. Anal Chim Acta 659: 122-128.

61. Krishnan S, Hvastkovs EG, Bajrami B, Choudhary D, Schenkman JB, et al (2008) Synergistic Metabolic Toxicity Screening Using Microsome/DNA Electrochemiluminescent Arrays and Nanoreactors. Anal Chem 80: 5279-5285.

62. Water quality -- Determination of the genotoxicity of water and waste water using the umu-test. ISO 13829: 2000.

63. Ben-Yoav H, Biran A, Pedahzur R, Belkin S, Buchinger S, et al. (2009)A Whole cell electrochemical biosensor for water genotoxicity bio-detection. Electrochim. Acta, special issue 54: 6113-6118.

64. Geng D, Zhang Z, Guo H (2012) Development of a Fish Cell Biosensor System for Genotoxicity Detection Based on DNA Damage-Induced Trans-Activation of p21 Gene Expression. Biosensors (Basel) 2: 318-340.

65. Ohno K, Tanaka-Azuma Y, Yoneda Y, Yamada TG (2005) Genotoxicity tes system based on p53R2 gene expression in human cells: Examination with 80 chemicals. Mutat Res 588: 47-57.

66. Ohno K, Ishihata K, Ohno K, Tanaka-Azuma Y, Yamada T (2008) A genotoxicity test system based on p53R2 gene expression in human cells: Assessment of its reactivity to various classes of genotoxic chemicals. Mutat Res 656: 27-35.

67. Hastwell PW, Webster TW, Tate M, Billinton N, Lynch AM, et al. (2009) Analysis of 75 marketed pharmaceuticals using the GADD45a-GFP 'GreenScreen HC' genotoxicity assay. Mutagenesis 24: 455-463. 
Citation: Starodub NF (2015) Genotoxicity: Modern Instrumental Approaches for its Control in Environmental Objects. J Biosens Bioelectron 6: 169. doi:10.4172/2155-6210.1000169

Page 8 of 8

68. Knight AW, Birrell L, Walmsley RM (2009) Development and validation of a higher throughput screening approach to genotoxicity testing using the GADD45a-GFP GreenScreen HC assay. J Biomol Screen 14: 16-30.

69. Zager V, Cemazar M, Hreljac I, Lah TT, Sersa G, et al. (2010) Development of human cell biosensor system for genotoxicity detection based on DNA damage-induced gene expression. Radiol Oncol 44: 42-51.

70. Su F, Zhang SC, Li HY, Guo HR (2007) In vitro acute cytotoxicity of neonicotinoid insecticide imidacloprid to gill cell line of flounder Paralichthy olivaceus. Chin J Oceanol Limnol 25: 209-214.

71. Starodub NF, Samodumova IM, Starodub VN (1995) Usage of organosilanes for integration of enzymes and immunocomponents with electrochemical and optical transducers. Sensors and Actuators B 24: 173-176.

72. Starodub NF, Rebriev AV (2007) Liquid photopolymerizable compositions as immobilized matrix of biosensors. Bioelectrochem 71: 29-32.
73. Starodub NF (2011) Photopolymerizable Materials in Biosensorics "Environmental Monitoring", Ed. Emma O. Ekundyo, InTech, November 18 299-326.

74. Premkumar RJ, Rosen R, Belkin Sh, Lev O (2002) Sol-gel luminescence biosensors: Encapsulation of recombinant $\mathrm{E}$. coli reporters in thick silicate films. Anal Chim Acta 462: 11-23.

75. Bettaieba F, Ponsonnet L, Lejeunec P, Ben Ouadad H, Marteleta C, et al. (2007) Immobilization of $E$. coli bacteria in three-dimensional matrices for ISFET biosensor design. Bioelectrochem 71: 118-125.

76. Ikariyama Y, Nishiguchi S, Koyama T, Kobatake E, Aizawa M, et al. (1997) Fiber-optic-based biomonitoring of benzene derivatives by recombinant $E$. coli bearing luciferase gene-fused TOL-plasmid immobilized on the fiber-optic end. Anal Chem 69: 2600-2605.

77. Lyngberg OK, Stemke DJ, Schottel JL, Flickinger MC (1999) A single-use luciferase-based mercury biosensor using Escherichia coli HB101 immobilized in a latex copolymer film. J Ind Microbiol Biotechnol 23: 668-676. 